\title{
Glucagon-like peptide-1 protects cardiomyocytes from advanced oxidation protein product-induced apoptosis via the PI3K/Akt/Bad signaling pathway
}

\author{
HUA ZHANG $^{1 *}$, ZHOUYI XIONG $^{1 *}$, JIAO WANG $^{2}$, SHUANGSHUANG ZHANG $^{1}$, \\ LEI LEI $^{1}$, LI YANG ${ }^{1}$ and ZHEN ZHANG $^{1}$ \\ ${ }^{1}$ Department of Endocrinology, Zhujiang Hospital of Southern Medical University, Guangzhou, Guangdong 510282; \\ ${ }^{2}$ Department of Endocrinology, The First Affiliated Hospital of Zhengzhou University, Zhengzhou, Henan 450052, P.R. China
}

Received January 13, 2015; Accepted November 24, 2015

DOI: $10.3892 / \mathrm{mmr} .2015 .4724$

\begin{abstract}
Cardiomyocyte apoptosis is a major event in the pathogenesis of diabetic cardiomyopathy. Currently, no single effective treatment for diabetic cardiomyopathy exists. The present study investigated whether advanced oxidative protein products (AOPPs) have a detrimental role in the survival of cardiomyocytes and if glucagon-like peptide-1 (GLP-1) exerts a cardioprotective effect under these circumstances. The present study also aimed to determine the underlying mechanisms. H9c2 cells were exposed to increasing concentrations of AOPPs in the presence or absence of GLP-1, and the viability and apoptotic rate were detected using a cell counting kit- 8 assay and flow cytometry, respectively. In addition, a phosphatidylinositol-4,5-bisphosphate 3-kinase (PI3K) inhibitor, LY294002, was employed to illustrate the mechanism of the antiapoptotic effect of GLP-1. The expression levels of the apoptotic-associated proteins, Akt, B-cell lymphoma (Bcl)-2, Bcl-2-associated death promoter (Bad), Bcl-2-associated X protein (Bax) and caspase- 3 were measured by western blotting. It was revealed that GLP-1 significantly attenuated AOPP-induced cell toxicity and apoptosis. AOPPs inactivated the phosphorylation of Akt, reduced the phosphorylation of Bad, decreased the expression of Bcl-2, increased the expression of Bax and the activation of caspase- 3 in H9c 2 cells. GLP-1 reversed the above changes induced by AOPPs and the protective effects of GLP-1 were abolished by the PI3K inhibitor, LY294002. In conclusion, the
\end{abstract}

Correspondence to: Dr Zhen Zhang or Dr Li Yang, Department of Endocrinology, Zhujiang Hospital of Southern Medical University, 253 Gongyedadao Middle, Guangzhou, Guangdong 510282, P.R. China

E-mail: zhangzhen2742@163.com

E-mail: 403276962@qq.com

*Contributed equally

Key words: glucagon-like peptide-1, cell apoptosis, advanced oxidative protein products, $\mathrm{PI} 3 \mathrm{~K} / \mathrm{Akt} / \mathrm{Bad}$ pathway present data suggested that GLP-1 protected cardiomyocytes against AOPP-induced apoptosis, predominantly via the $\mathrm{PI} 3 \mathrm{~K} / \mathrm{Akt} / \mathrm{Bad}$ pathway. These results provided a conceivable mechanism for the development of diabetic cardiomyopathy and rendered a novel application of GLP-1 exerting favorable cardiac effects for the treatment of diabetic cardiomyopathy.

\section{Introduction}

The incidence and prevalence of diabetes mellitus (DM) are increasing globally (1). Cardiovascular complications are the leading causes of morbidity and mortality in patients with diabetes. Among them, diabetic cardiomyopathy (DCM) is defined as a distinct primary disease process, independent of coronary artery disease, hypertension or any other cardiovascular diseases, which leads to ventricular dysfunction and heart failure (2). However, the pathogenesis of DCM remains to be elucidated. To date, certain cellular and molecular defects are believed to be responsible for the pathogenesis of DCM, including glucotoxicity, altered lipid metabolism, lipotoxicity, oxidative stress, abnormal calcium handling, protein kinase $\mathrm{C}$ signaling, apoptosis/inflammation/fibrosis and mitochondrial dysfunction (3). In particular, growing evidence has demonstrated that apoptosis of cardiomyocytes is vital in the development of DCM (4,5). Therefore, inhibition of cardiac apoptosis is of great importance in the prevention and treatment of DCM (6).

Advanced oxidative protein products (AOPPs) are the dityrosine-containing and cross-linking protein products, which are formed during oxidative stress by the reaction between proteins and chlorinated oxidants (7). AOPPs were initially discovered in the plasma of patients with uremia and undergoing dialysis, and are considered as a novel marker of oxidative stress. Increased levels of plasma AOPPs were demonstrated in patients with DM, coronary artery disease and metabolic syndrome (8-10). In addition, AOPPs were significantly higher in the diabetic group with vascular complications compared with the group without complications (11). In vitro, incubation of AOPPs with human umbilical vein endothelial cells induced superoxide generation, activated NAD $(\mathrm{P}) \mathrm{H}$ oxidase, extracellular-signal regulated kinase (ERK)1/2 and p38, and 
promoted nuclear translocation of NF- $\mathrm{NB}$, by bonding to the receptor for advanced glycation end products (RAGEs) (12). In experimental models, accumulation of AOPPs activated the p53/Bax/caspase-dependent proapoptotic pathway via RAGE and resulted in podocyte apoptosis (13). However, the exact role of AOPPs in the myocardial cells of DCM remains to be elucidated.

Glucagon-like peptide-1 (GLP-1) is a multifunctional hormone secreted from intestinal endocrine $\mathrm{L}$ cells and is widely used for the treatment of diabetes. As well as its effects on glucose control, GLP-1 reduces gastric emptying, inhibits appetite and exhibits a protective effect on cardiovascular diseases $(14,15)$. The GLP-1 receptor (GLP-1R) was identified in the heart and vascular tissue, in addition to pancreatic $\alpha$ and $\beta$ cells $(16,17)$. A previous study demonstrated that the GLP-1R agonist, liraglutide, inhibits endothelial cell dysfunction and alleviates atherosclerotic injury (14). In rats with chronic heart failure, subcutaneous infusion with GLP-1 and its analogue, exenatide, improves cardiac function, cardiac remodeling and survival (18). Furthermore, GLP-1 directly protects cardiomyocytes from hypoxia/reoxygenation injury, predominantly by inhibiting their apoptosis (19) and protects vascular endothelial cells against AGE-induced apoptosis (20). However, whether GLP-1 has a protective effect on AOPP-treated cardiomyocytes remains to be elucidated.

Therefore, the present study aimed to investigate whether AOPPs have a detrimental role in the survival of cardiomyocytes and if GLP-1 exerts cardioprotective effects under certain circumstances. The present study focussed on the effect of GLP-1 on the apoptosis of H9c2 myocardial cells induced by AOPPs and its underlying mechanism. It was demonstrated that GLP-1 alleviates AOPP-induced apoptosis via the PI3K/Akt/Bad pathway in $\mathrm{H} 9 \mathrm{c} 2$ cells. In conclusion, these data presented a theoretical foundation and novel insight into the pathogenic and therapeutic strategy of DCM.

\section{Materials and methods}

Materials. Dulbecco's modified Eagle's medium (high glucose) and phosphate-buffered saline (PBS) were purchased from Hyclone (Logan, UT, USA). Fetal bovine serum (FBS), penicillin-streptomycin solution and $0.25 \%$ Trypsin-EDTA were purchased from (Thermo Fisher Scientific, Inc., Waltham, MA, USA). Dimethyl sulfoxide, diethyl pyrocarbonate, rat serum albumin (RSA), bovine serum albumin (BSA), paraformaldehyde, Triton X-100, 4',6-diamidino-2-phenylindole (DAPI), GLP-1 (7-36 amide) and the amebocyte lysate assay kit were all purchased from Sigma-Aldrich (St Louis, MO, USA). The following antibodies were purchased from Cell Signaling Technologies (Boston, MA, USA): Rabbit monoclonal phosphorylated (p)-Akt (Ser473; cat. no. CST4060P), rabbit monoclonal anti-Akt (cat. no. CST4695), rabbit anti-B-cell lymphoma (Bcl)-2 (cat. no. CST2876) rabbit monoclonal p-Bcl-2-associated death promoter (Bad; Ser136; cat. no. CST4366P), rabbit anti-Bcl-2 associated $\mathrm{X}$ protein (Bax; cat. no. CST2772) and rabbit anti-caspase-3 (cat. no . CST9662). Mouse anti-RAGE antibody (cat. no. SC33662) was provided by Santa Cruz Biotechnology, Inc. (Heidelberg, Germany). Rabbit anti-GLP1R antibody (cat. no. ab39072) was purchased from Abcam (Cambridge, MA, USA). A
Cell Counting kit (CCK)-8 was purchased from Dojindo Laboratories (Kumamoto, Japan). LY294002 and a Hoechst 33258 Staining kit were purchased from Beyotime Institute of Biotechnology (Haimen, China). RNAiso plus, SYBR Premix EX Taq II kit and PrimeScript ${ }^{\mathrm{TM}}$ RT reagent kit were purchased from Takara Biotechnology Co., Ltd. (Dalian, China). Hypochlorous acid $(\mathrm{HOCl})$ was purchased from Fluke (Buchs, Swizerland). An annexin V-fluorescein isothiocyanate (FITC) apoptosis detection kit was purchased from eBioscience (San Diego, CA, USA). A bicinchoninic assay protein assay kit was purchased from Keygen Biotech Co., Ltd. (Nanjing, China). Rabbit anti-GAPDH antibody, anti-rabbit or anti-mouse horseradish peroxidase-conjugated secondary immunoglobulin (Ig)G were obtained from Wuhan Boster Biological Technology, Ltd. (Wuhan, China). FITC-labeled anti-mouse $\mathrm{IgG}$ and anti-rabbit IgG were purchased from EarthOx, LLC (San Francisco, CA, USA).

Cell culture. The H9c2 (2-1) cells (21) were a generous gift from the Department of Cardiology, Nanfang Hospital (Guangzhou, China). The H9c2 cells were cultured in Dulbecco's modified Eagle's medium (high glucose), containing 10\% FBS and $1 \%$ penicillin-streptomycin solution in a $5 \%$ carbon dioxide atmosphere at $37^{\circ} \mathrm{C}$. The cells were subcultured every 2-3 days at a ratio of $1: 2$ or $1: 3$.

AOPPs preparation and determination. AOPPS-RSA was prepared in vitro, as previously described $(7,13)$. Briefly, $20 \mathrm{mg} / \mathrm{ml} \mathrm{RSA}$ solution was mixed and placed with $40 \mathrm{mmol} / 1 \mathrm{HOCl}$ in $\mathrm{PBS}$ for $30 \mathrm{~min}$ at $37^{\circ} \mathrm{C}$. The prepared samples were dialyzed against PBS for $24 \mathrm{~h}$ to remove free $\mathrm{HOCl}$ and passed through a Detoxi-Gel column (Pierce, Rockford, IL, USA) to remove contaminated endotoxin. A total of $20 \mathrm{mg} / \mathrm{ml} \mathrm{RSA}$ solution was mixed with isometric PBS as a comparison. The content of AOPPs in the AOPPs-RSA and unmodified RSA were 70.7 and $0.11 \mathrm{nmol} / \mathrm{mg}$ protein, respectively. Endotoxin levels in the AOPPs-RSA and unmodified RSA were measured with the amebocyte lysate assay kit and were determined to be $>0.25 \mathrm{EU} / \mathrm{ml}$.

Cell viability. The H9c2 cells were seeded into 96-well plates at a density of $2.5 \times 10^{3}$ and were treated with the indicated concentrations of AOPPs-RSA and GLP-1. Following incubation for $24 \mathrm{~h}$, the medium was replaced with $10 \% \mathrm{CCK}-8$ solution for $2 \mathrm{~h}$ at $37^{\circ} \mathrm{C}$. The absorbance was measured at $450 \mathrm{~nm}$ with a microplate reader (EXL808; BioTek, Winooski, VT, USA), according to the manufacturer's instructions.

Cell apoptosis. Each group of cells were detected by double staining with FITC-conjugated annexin $\mathrm{V}$ and propidium iodide (PI). The collected cells were washed twice with PBS and stained with $5 \mu \mathrm{l}$ annexin V-FITC for $15 \mathrm{~min}$ in the dark in binding buffer (eBioscience, San Diego, CA, USA). Subsequently, $10 \mu \mathrm{l}$ PI was added at room temperature for 5 mins. Cell apoptosis was determined using a FACSVerse flow cytometer (BD Biosciences, San Jose, CA, USA) using the FACSuite program (BD Biosciences).

Hoechst33258staining.Following treatment, theH9c2cellswere fixed overnight at $4^{\circ} \mathrm{C}$, and were subsequently permeabilized 
and stained with $10 \mu \mathrm{g} / \mathrm{ml}$ Hoechst 33258 for $5 \mathrm{~min}$ at room temperature. The morphological changes were observed under a fluorescence microscope (Axio Scope A1; Carl Zeiss, Jena, Germany) at a wavelength of $350 \mathrm{~nm}$.

Immunofluorescence assay. Following treatment, the cells were fixed in $4 \%$ paraformaldehyde for $15 \mathrm{~min}$ and permeabilized with Triton X-100 for $15 \mathrm{~min}$ at room temperature. Following washing the cells twice with PBS, the cells were blocked in $1 \% \mathrm{BSA}$ for $30 \mathrm{~min}$ at room temperature. The cells were subsequently incubated overnight at $4^{\circ} \mathrm{C}$ with primary antibody (RAGE, 1:100; GLP-1, 1:100) in 1\% BSA. Following washing twice with PBS, the cells were incubated with FITC-labeled anti-mouse or anti-rabbit IgG secondary antibodies (1:200) for $1 \mathrm{~h}$ at room temperature. Finally, the cells were stained with $100 \mathrm{ng} / \mathrm{ml}$ DAPI for $2 \mathrm{~min}$ at room temperature and immunofluorescent images were captured using a fluorescence microscope (Axio Scope A1; Carl Zeiss).

Western blot analysis. Following treatment, the cellular proteins were extracted using radioimmunoprecipitation lysis buffer (Sangon Biotech Co., Ltd, Shanghai, China) for $30 \mathrm{~min}$ at $4^{\circ} \mathrm{C}$ and centrifuged at $250 \mathrm{x}$ g for $20 \mathrm{~min}$ at $4^{\circ} \mathrm{C}$. The protein concentration was measured using a bicinchoninic assay kit on a EXL808 microplate reader. The proteins (50 $\mu \mathrm{g})$ were separated on $12 \%$ SDS-polyacrylamide gels (Whiga, Guangdong, China) and were transferred onto polyvinylidene fluoride membranes (Bio-Rad Laboratories, Hercules, CA, USA). The membranes were blocked in $5 \%$ non-fat milk in Tris-buffered saline, containing $0.1 \%$ Tween-20 (TBST), for $2 \mathrm{~h}$ at room temperature and were subsequently immunoblotted with primary antibodies for $2 \mathrm{~h}$ at room temperature. Antibodies against p-Akt (1:2,000), Akt (1:1,000) p-Bad (1:1,000), Bax (1:1,000), Bcl-2 (1:1,000), caspase-3 (1:1,000), RAGE (1:100) and GLP-1R $(1: 1,000)$ were used. Following washing three times with TBST, the membranes were incubated with anti-rabbit or anti-mouse horseradish peroxidase-conjugated secondary $\operatorname{IgG}(1: 2,500)$ at room temperature for $1 \mathrm{~h}$. The protein bands were visualized using an enhanced chemiluminescence kit (EMD Millipore, Billerica, MA, USA).

Reverse transcription-quantitative polymerase chain reaction $(R T-q P C R)$. The total RNA was extracted using RNAiso Plus, according to the manufacturer's instructions. The purity of each RNA sample was measured using a Nanodrop $2000 \mathrm{spec}$ trophotometer (Thermo Fisher Scientific, Inc.). To remove genomic DNA contamination, the RNA samples were treated with gDNA Eraser (Takara Biotechnology Co., Ltd.) at $42^{\circ} \mathrm{C}$ for $2 \mathrm{~min}$. The complementary DNA was synthesized in a $20 \mu 1$ reaction system, using the PrimeScript $\mathrm{RT}$ reagent kit at $37^{\circ} \mathrm{C}$ for $15 \mathrm{~min}$ and $85^{\circ} \mathrm{C}$ for $5 \mathrm{sec}$. The primers used were as follows: Rat RAGE, forward: 5'-GGGACAGTGTGG CTCGAATC-3' and reverse: 5'-TCCCAAGCCTGTTAG TTGCC-3'; rat GLP-1R, forward: 5'-AATGCAGACTCG CGAAGTCC-3' and reverse: 5'-TGACGAAGCGTAGGG TTCCT-3'; GAPDH (internal control), forward: 5'-AGGGCT GCCTTCTCTTGTGA-3' and reverse 5'-AACTTGCCGTGG GTAGAGTCA-3'. RT-qPCR was performed using the SYBR Premix EX Taq II kit on an ABI 7300 system (ABI, Foster City, CA, USA). The cycling conditions were $93^{\circ} \mathrm{C}$ for $15 \mathrm{~min}$, followed by 40 cycles of $93^{\circ} \mathrm{C}$ for $15 \mathrm{sec}, 55^{\circ} \mathrm{C}$ for $25 \mathrm{sec}$ and $72^{\circ} \mathrm{C}$ for $25 \mathrm{~min}$. The data were normalized against GAPDH and the negative control. Data analysis was performed using the $2^{-\Delta \Delta \mathrm{Cq}}$ method.

Statistical analysis. All data are expressed as the mean \pm standard deviation. Differences between groups were assessed by one-way or Welch analysis of variances (equal variances not assumed) once normality was confirmed. For pairwise comparison, a least significant difference test or Dunnett's T3 test was used when the equal variances were not assumed. Spearman's rank correlation was used for correlation analysis. $\mathrm{P}<0.05$ was considered to indicate a statistically significant difference. All analyses were performed with SPSS 13.0 software (SPSS Inc., Chicago, IL, USA).

\section{Results}

GLP-1 attenuated AOPP-induced toxicity in H9c2 cells. To confirm if AOPPs are toxic on cell viability, a CCK-8 assay was performed in AOPP-treated H9c2 cells. As shown in Fig. 1A, incubation with AOPPs-RSA for $24 \mathrm{~h}$ significantly inhibited cell viability ( 84.2 to $64.5 \%$ ) in a dose-dependent manner $(r=-0.797, P=0.000)$ while RSA caused no effect. In addition, $\mathrm{H} 9 \mathrm{c} 2$ cells were incubated with $1 \mu \mathrm{g} / \mathrm{ml}$ AOPP-RSA for $24 \mathrm{~h}$ in the presence or absence of different concentrations of GLP-1. Compared with AOPP-RSA, GLP-1 partly restored cell viability in a dose-dependent manner $(\mathrm{r}=0.698, \mathrm{P}=0.004)$, with a peak at $50 \mathrm{nmol} / \mathrm{l}(97.9 \%$; Fig. 1B). Therefore, subsequent experiments were performed using $1 \mu \mathrm{g} / \mathrm{ml}$ AOPPs-RSA and $50 \mathrm{nmol} / 1 \mathrm{GLP}-1$. These results demonstrated that GLP-1 protects AOPPs-RSA-induced toxicity in H9c2 cells.

GLP-1 attenuates AOPP-induced apoptosis in H9c2 cells. The proapoptotic effect of AOPPs on $\mathrm{H} 9 \mathrm{c} 2$ cells was assessed. The morphological changes were detected by staining cells with Hoechst 33258 (Fig. 1C). An increase in the number of apoptotic cells was observed in the AOPP-treated cells and a decrease in the AOPPs- and GLP-1-treated cells. Following co-incubation with LY294002, the number of apoptotic cells increased. As shown in Fig. 1D, cells incubated with AOPPs-RSA exhibited a significant increase in the apoptotic rate (15.8\%) compared with the control group $(1.3 \% ; \mathrm{P}<0.01)$. This increment was blunted in the presence of GLP-1 $(9.7 \%, \mathrm{P}<0.01$, vs. the AOPPs group). The PI3K inhibitor, LY294002, was used to determine the mechanisms behind the antiapoptotic effects of GLP-1. The apoptotic rate of this group was significantly increased (18.4\%, P<0.01, vs. the AOPPs + GLP-1 group). These data indicated that GLP-1 attenuates AOPP-RSA-induced apoptosis in $\mathrm{H} 9 \mathrm{c} 2$ cells and this effect may be associated with the PI3K pathway.

GLP-1 may protect AOPP-induced apoptosis by downregulating the expression of $R A G E$. Previously, AOPPs were confirmed to exert their proapoptotic effect via RAGE (22). It was confirmed that the expression of RAGE was upregulated by exposure to AOPP-RSA in a dose-dependent manner (Fig. 2A) in H9c2 cells. In addition, GLP-1 (50 nM for $24 \mathrm{~h}$ ) significantly downregulated the protein and mRNA expression levels of RAGE (Fig. 2B and C). Therefore, GLP-1 may protect 
A

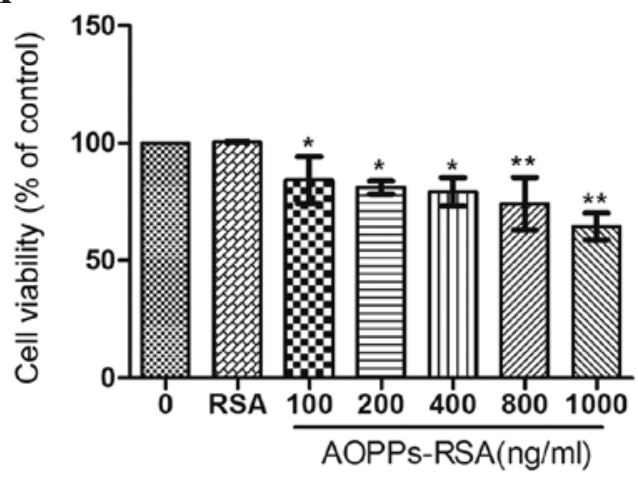

C

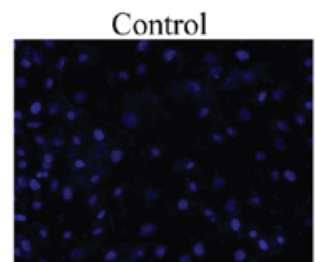

AOPPs-RSA

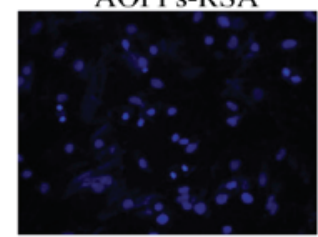

$\mathrm{AOPP}+\mathrm{GLP}-1$

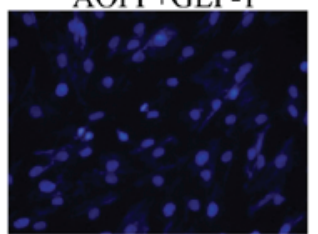

RSA

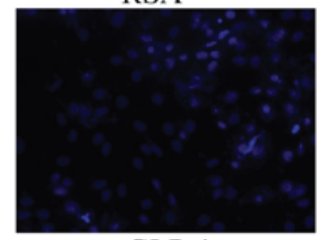
GLP-1

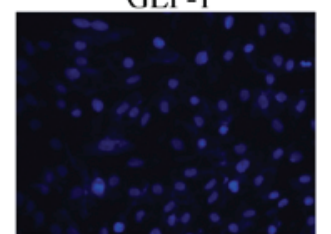

AOPP+GLP-1+LY294002
B

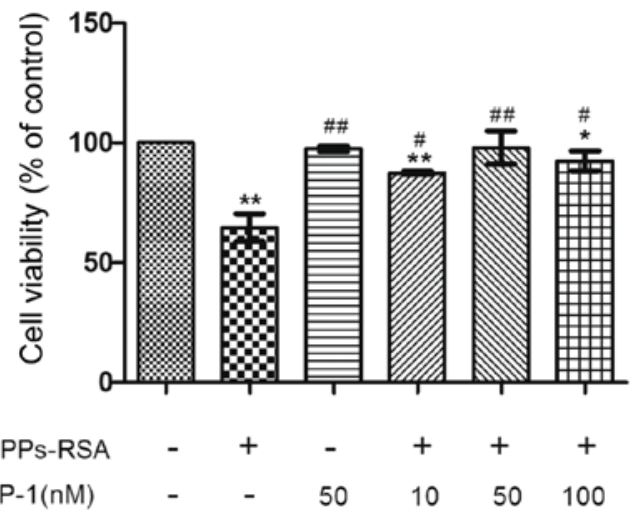

D

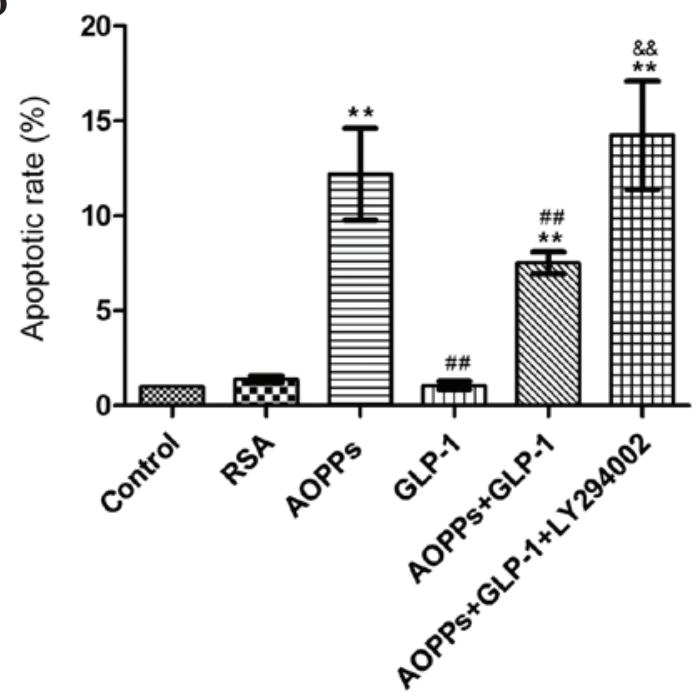

Figure 1. GLP-1 attenuated AOPPs-RSA-induced toxicity and apoptosis in H9c2 cells. The cell viability, morphological changes and apoptotic rates were assessed using a cell counting kit-8 assay, Hoechst 33258 staining and flow cytometry, respectively. (A) The cells were incubated with RSA (1 $\mu \mathrm{g} / \mathrm{ml})$, or increasing concentrations of AOPPs-RSA for $24 \mathrm{~h}$. AOPPs-RSA inhibited cell viability in a dose-dependent manner. (B) The cells were incubated with $1 \mu \mathrm{g} / \mathrm{ml}$ AOPPs-RSA for $24 \mathrm{~h}$ in the presence or absence of different concentrations of GLP-1. GLP-1 improved cell viability in a dose-dependent manner. (C) The morphological changes in $\mathrm{H} 9 \mathrm{c} 2$ cells were detected using a fluorescence microscope. Chromatin condensation and nuclear fragmentation represented apoptotic cells, while the diffuse blue fluorescence represented normal cells (magnification, x200). (D) The apoptotic rate of each treatment was determined. The data are expressed as the mean \pm standard deviation of three independent experiments $\left({ }^{*} \mathrm{P}<0.05\right.$ and ${ }^{* *} \mathrm{P}<0.01$, vs. control; ${ }^{\#} \mathrm{P}<0.05$ and ${ }^{\# \#} \mathrm{P}<0.01$, vs. AOPPs-treated cells; \&\&P<0.01, vs. AOPPs + GLP-1-treated group). GLP-1, Glucagon-like peptide-1; AOPPs, advanced oxidation protein products; RSA, rat serum albumin.

AOPP-induced apoptosis by downregulating the expression of RAGE.

GLP-1 exerts its protective function via the GLP-1R in $H 9 c 2$ cells. The presence of the GLP-1R has been identified in different cells and the interaction of GLP-1 with the GLP-1R has been determined to be responsible for multiple function of GLP-1 (23). Therefore, the present study confirmed that H9c2 cells express the GLP-1R (Fig. 3A). In addition, the mRNA and protein expression levels of GLP-1R were upregulated by exposure to GLP-1 itself (Fig. 3B and C). Therefore, it was speculated that GLP-1 may exert its protective function via the GLP-1R in H9c2 cells.

GLP-1 prevents AOPP-inducedapoptosis via the PI3K/Akt/Bad pathway in H9c2 cells. The role of the PI3K/Akt/Bad pathway and GLP-1 in preventing AOPP-induced apoptosis in H9c2 cells was investigated. Firstly, AOPP-RSA significantly inactivated
Akt phosphorylation at Ser473 (Fig. 4A) and subsequently reduced Bad phosphorylation at Ser136 (Fig. 4B) compared with the control and RSA group. In addition, a decrease of the anti-apoptotic protein, Bcl-2 (Fig. 4C), and an increase of the proapoptotic protein, Bax (Fig. 4D), was demonstrated in AOPPs-RSA treated cells. In addition, the elevated expression of caspase-3 was demonstrated by western blotting (Fig. 4E).

However, these changes were reversed in the presence of GLP-1 (Fig. 4). Furthermore, the effect of GLP-1 was abrogated following treatment of the $\mathrm{H} 9 \mathrm{c} 2$ cells with a PI3K inhibitor,LY294002 (Fig. 4). These results indicated that GLP-1 prevented AOPP-induced apoptosis via the PI3K/Akt/Bad pathway in $\mathrm{H} 9 \mathrm{c} 2$ cells.

\section{Discussion}

The major findings of the present study were as follows: i) AOPPs induced apoptosis in H9c2 cells; ii) GLP-1 prevented 
A

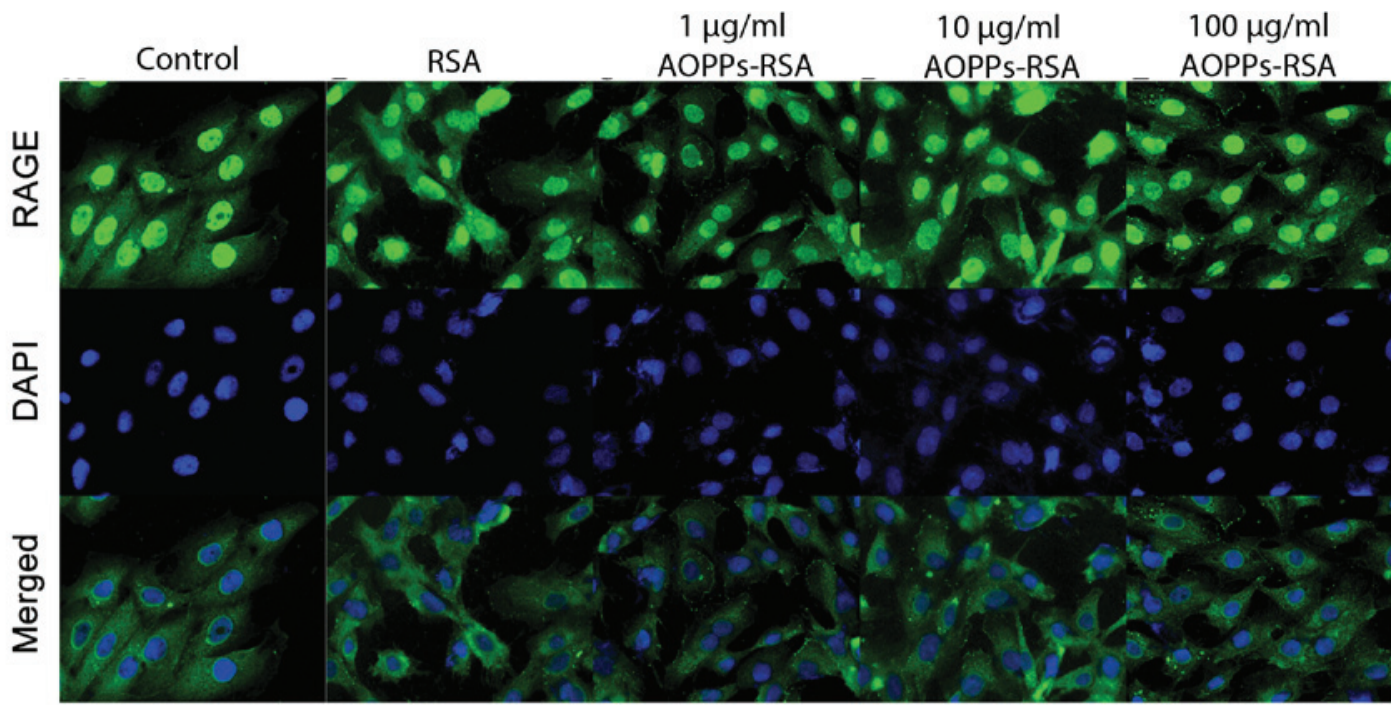

B
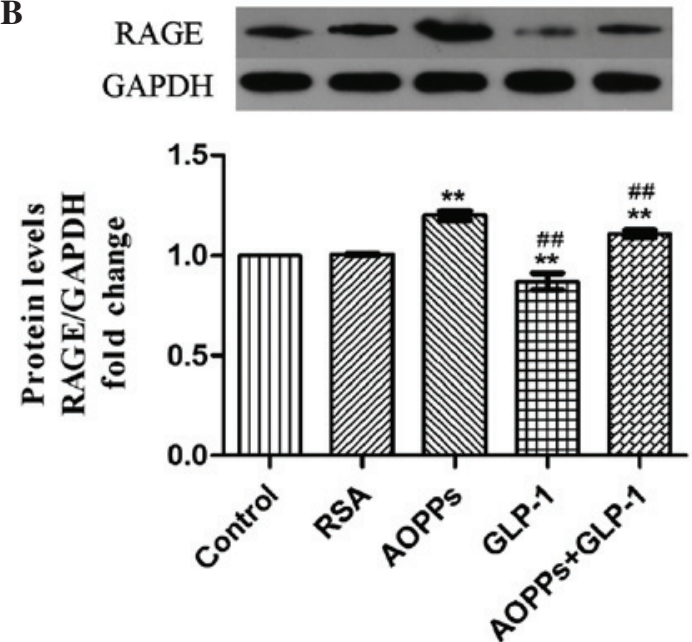

C

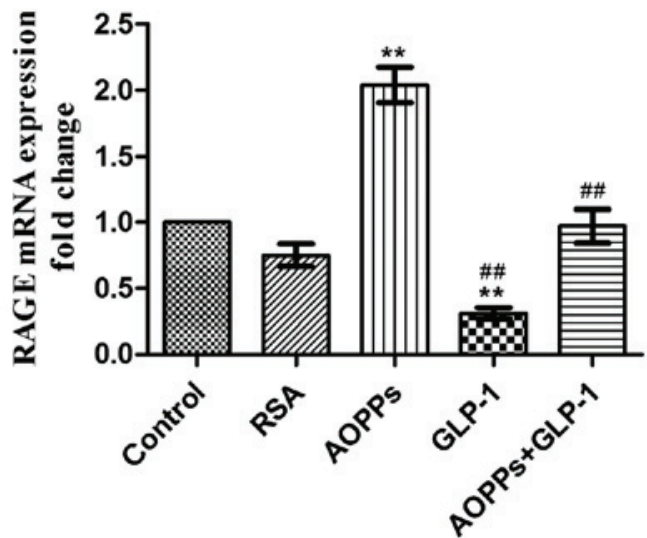

Figure 2. GLP-1 downregulates the expression of RAGE in H9c2 cells. (A) H9c2 cells were immunostained with anti-mouse RAGE primary antibody and fluorescein isothiocyanate-conjugated secondary antibody (green), and were counterstained with DAPI (blue). The expression of RAGE was upregulated by exposure of increasing concentrations of AOPPs-RSA for $24 \mathrm{~h}$ (magnification, $\mathrm{x} 400$ ). (B) GLP-1 significantly decreased the protein expression of RAGE, as determined by western blotting. (C) GLP-1 significantly decreased the mRNA expression of RAGE as determined by reverse transcription-quantitative polymerase chain reaction. The data are expressed as the mean \pm standard deviation of three independent experiments ${ }^{* *} \mathrm{P}<0.01$, vs. control; ${ }^{\# \#} \mathrm{P}<0.01$, vs. AOPPs-RSA-treated cells). GLP-1, Glucagon-like peptide-1; AOPPs, advanced oxidation protein products; RSA, rat serum albumin; RAGE, receptor for advanced glycation end product; DAPI, 4',6-diamidino-2-phenylindole.

AOPP-induced cell apoptosis; iii) GLP-1 exerted these cardioprotective effects predominantly via the PI3K/Akt/Bad pathway. This is the first study, to the best of our knowledge, to confirm that GLP-1 protected against AOPP-induced apoptosis in $\mathrm{H} 9 \mathrm{c} 2$ cells.

AOPPs, as novel markers of oxidative stress, have been explored in several cell types. Previous studies have investigated the proapoptotic effect of AOPPs on vascular endothelial cells (12), podocytes (13), intestine epithelial cells (24) and rat osteoblast-like cells (25). However, previous studies, which focus on the effect of AOPPs in cardiomyocytes are rare. Valente et al (26) demonstrated that AOPPs induce neonatal and adult mouse cardiomyocyte death via Nox2/Rac1/superoxide-dependent TRAF3IP2/JNK signaling. In the present study, it was revealed that AOPP-treatment significantly increased the apoptotic rate of a rat ventricular myoblast cell line, H9c2. In addition, AOPPs decreased the phosphorylation of Akt and subsequently reduced the phosphorylation of Bad. This data suggested that AOPPs induce H9c2 cell apoptosis and that the Akt/Bad pathway may be involved. Cardiomyocyte apoptosis is a major event in the pathogenesis of $\operatorname{DCM}(27,28)$. In addition, DM is associated with an increased production of AOPPs $(8,11,29,30)$. In this regard, the present study hypothesized that AOPP-induced apoptosis may be involved in the development of DCM. Since adult cardiomyocytes possess a finite capacity to proliferate, the loss of cardiomyocytes results in cardiac dysfunction and heart failure (31). Therefore, suppression of cardiomyocyte apoptosis is a crucial strategy for the prevention of DCM.

GLP-1 has been widely investigated in recent years. Numerous studies have confirmed that GLP-1 has anti-apoptotic functions in different types of cell, including pancreatic $\beta$ cells (32), cholangiocytes (33), neurons (34) and cardiomyocytes (35). Consistent with previous reports, the present study 

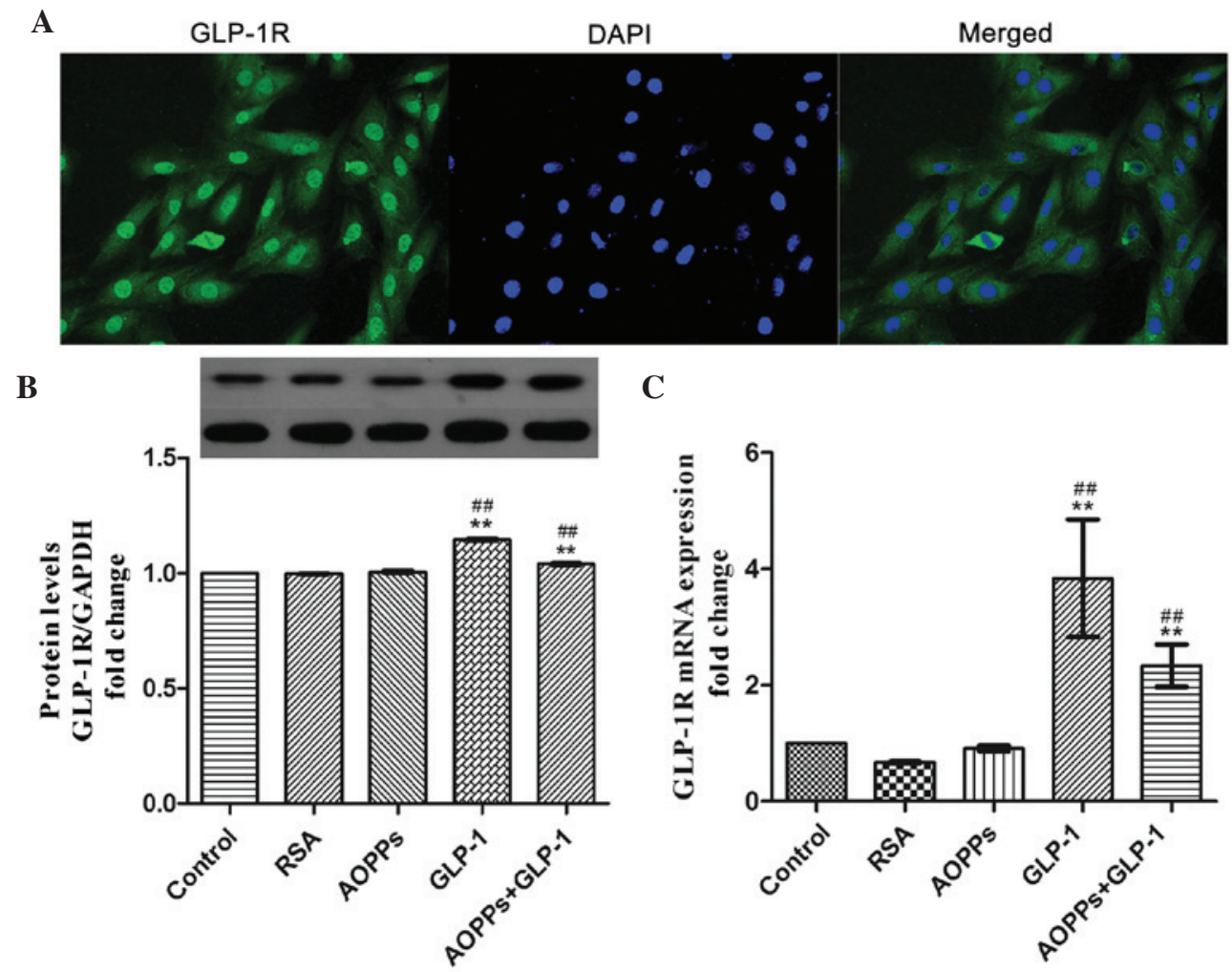

C

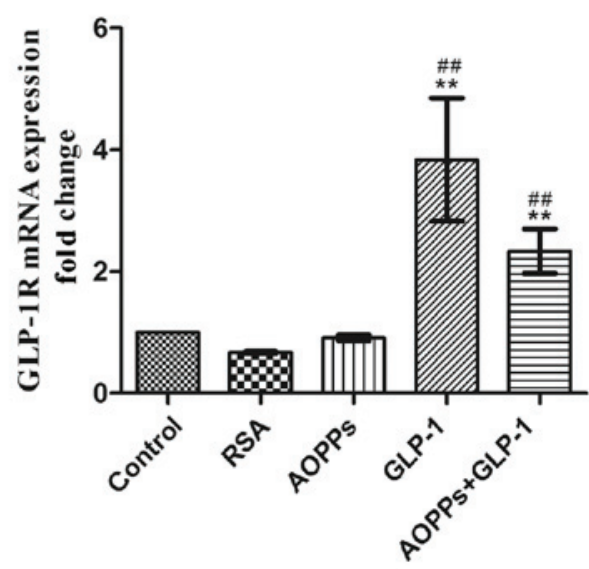

Figure 3. GLP-1 exerts its protective function via the GLP-1 receptor in H9c2 cells. (A) H9c2 cells were immunostained with anti-rabbit GLP-1R primary antibody and fluorescein isothiocyanate-conjugated secondary antibody (green), and counterstained with DAPI (blue; magnification, x200). (B) GLP-1 significantly increased the expression of the GLP-1R, as determined by western blot analysis. (C) The mRNA expression of GLP-1R was increased following exposure to GLP-1 $(50 \mathrm{nM})$ for $24 \mathrm{~h}$, as measured by reverse transcription-quantitative polymerase chain reaction. The data are expressed as the mean \pm standard deviation of three independent experiments $\left({ }^{* *} \mathrm{P}<0.01\right.$, vs. control; ${ }^{\# /} \mathrm{P}<0.01$, vs. AOPPs-treated cells). GLP-1, Glucagon-like peptide-1; GLP-1R, GLP-1 receptor; AOPPs, advanced oxidation protein products; RSA, rat serum albumin; DAPI, 4',6-diamidino-2-phenylindole.

indicated that GLP-1 (7-36) inhibits AOPP-induced toxicity and apoptosis in $\mathrm{H} 9 \mathrm{c} 2$ cells. The present study next investigated the mechanisms of this antiapoptotic effect of GLP-1.

Cytoprotective actions of GLP-1 have been substantiated in the heart. Notably, GLP-1 directly interacts with the myocardium due to the presence of the receptor of the GLP-1R $(36,37)$. The present results demonstrated that the GLP-1R was expressed in H9c2 cells. Therefore, it is possible that GLP-1 can exhibit protective effect on H9c2 cells. AOPPs and AGEs are similar in structure and biological activity. AOPPs are demonstrated to induce cardiomyocyte death by interacting with a member of the immunoglobulin superfamily of cell surface molecules, RAGE (26). In the present study, it was confirmed that the expression of RAGE occurred in $\mathrm{H} 9 \mathrm{c} 2$ cells and was upregulated following exposure to increasing concentration of AOPPs-RSA. In addition, it was revealed that GLP-1 downregulated not only the mRNA expression of RAGE, but also the protein expression. These data may partly explain why GLP-1 can inhibit AOPP-induced apoptosis in H9c2 cells.

The mechanisms underlying the anti-apoptotic effect of GLP-1 on the heart have been investigated by in vivo and in vitro experiments. For instance, in murine HL-1 cardiomyocytes, GLP-1 prevents the exposure of phosphatidylserine, the increase of the Bax:Bcl-2 ratio, the activation of Bad, mitochondrial membrane depolarization, the release of cytochrome $c$, the activation of caspase- 3 and DNA fragmentation, induced by staurosporine (35). GLP-1R agonist, exendin-4, attenuates high glucose-induced cardiomyocyte apoptosis in association with decreased endoplasmic reticulum stress and markers of enhanced SERCA2a activity (38). Furthermore, exenatide increased the expression levels of p-Akt and Bcl-2, decreased the activity of caspase-3, reduced infarct size, and prevented deterioration of systolic and diastolic cardiac function in a porcine model of myocardial ischaemia/reperfusion (39). However, the mechanisms of GLP-1 on the AOPP-induced apoptosis remain to be elucidated. Therefore, the present study investigated the PI3K/Akt pathway as a candidate for the underlying mechanisms.

It has been reported that GLP-1 and its analogues inhibit cardiomyocyte apoptosis by regulating numerous apoptotic-associated pathways, including the PI3K (40), cAMP (23) and ERK1/2 pathways (41). The present study demonstrated that when treated with a PI3K inhibitor, LY294002, the apoptotic rate of GLP-1 and AOPPs co-treated cells was increased, indicating that GLP-1 requires activation of the PI3K pathway to prevent AOPP-induced apoptosis in $\mathrm{H} 9 \mathrm{c} 2$ cells. $\mathrm{PI} 3 \mathrm{~K}$ is a type of cellular protein kinase, which is involved in cell survival, growth and proliferation. Activated PI3K subsequently phosphorylated its downstream Ser/Thr protein kinase, Akt, also known as protein kinase B. The activation of the Akt pathway provides cells with a survival signal, which allows them to withstand apoptotic stimuli (42). Numerous reports elucidated the important roles of activating the PI3K/Akt signaling pathway in competing cell apoptosis in the heart (43-45). Bad, a Bcl-2 family member, can combine with 
A
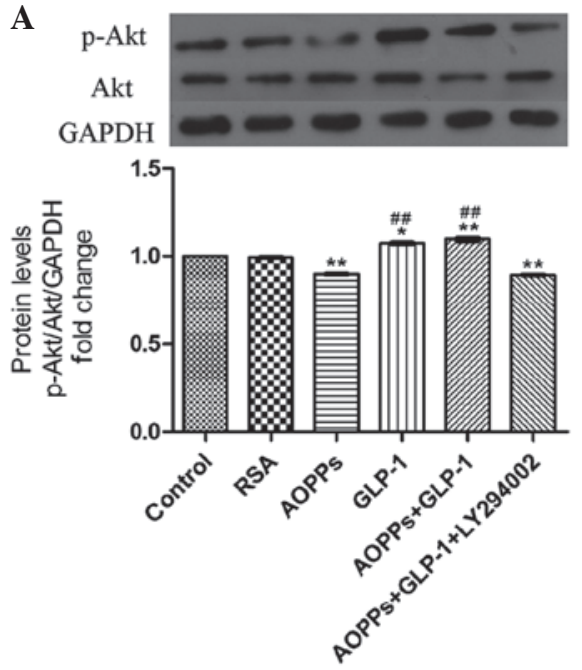

D
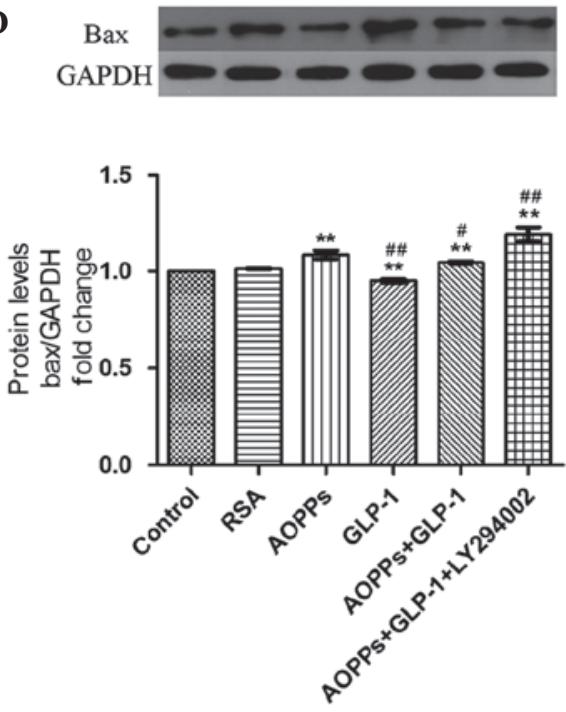

B
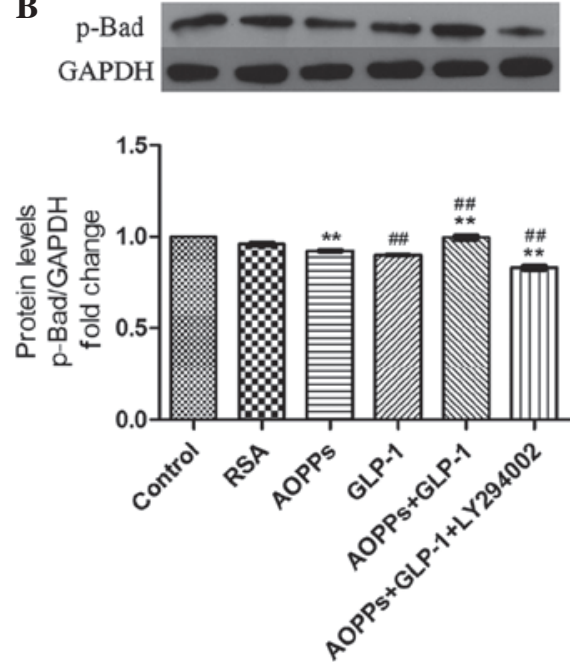

C Bcl-2
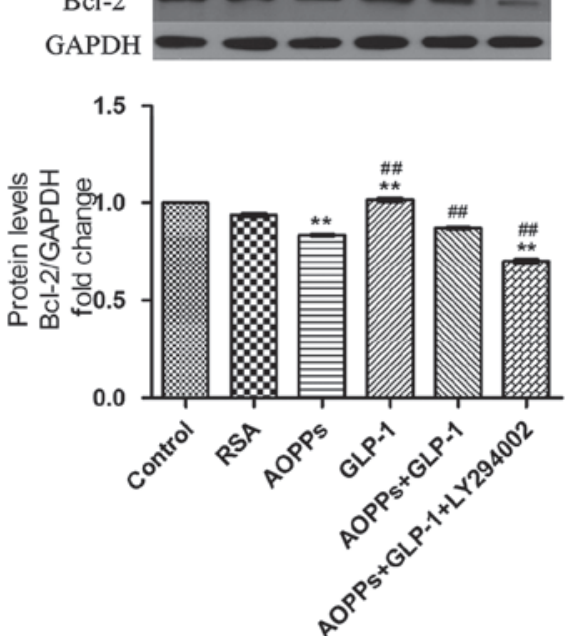

E active-caspase-3 caspase-3

GAPDH

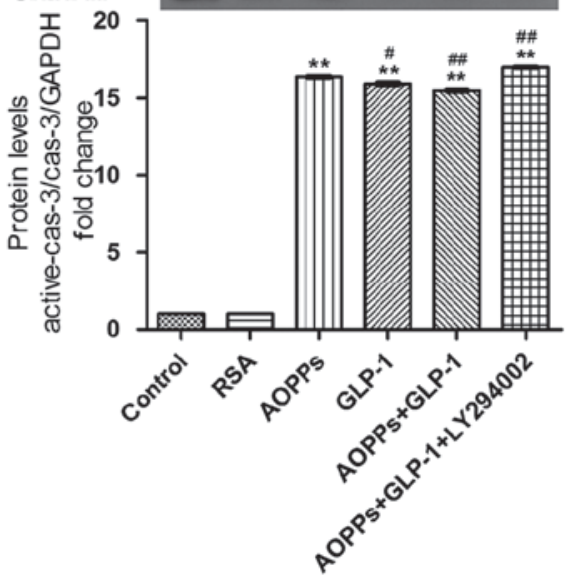

Figure 4. GLP-1 prevents AOPPs-induced apoptosis via the PI3K/Akt/BAD pathway in H9c2 cells. The cells were exposed to AOPPs-RSA ( $1 \mu$ g/ml), GLP-1 $(50 \mathrm{nM})$ or LY294002 $(10 \mu \mathrm{M})$ for $24 \mathrm{~h}$. The protein expression levels were detected by western blotting. GLP-1 reversed AOPPs-RSA-induced (A) p-Akt and (B) p-bad inactivation. LY294002 significantly inhibited the effect of GLP-1. AOPPs-RSA decreased the expression of (C) Bcl-2 and increased the expression of (D) Bax and (E) activated caspase-3. GLP-1 reversed these effects, however, was suppressed by LY294002. The data are expressed as the mean \pm standard deviation of three independent experiments $\left({ }^{*} \mathrm{P}<0.05\right.$ and ${ }^{* *} \mathrm{P}<0.01$, vs. control; ${ }^{\#} \mathrm{P}<0.05$ and ${ }^{\# \#} \mathrm{P}<0.01$, vs. AOPPSs-RSA treated cells). GLP-1, Glucagon-like peptide-1; AOPPs, advanced oxidation protein products; RSA, rat serum albumin; p-, phosphorylated; Bcl, B-cell lymphoma; Bax, Bcl-2-associated X protein; Bad, Bcl-2-associated death promoter.

antiapoptotic factor Bcl-2 or Bcl-xL to form a proapoptotic complex. However, when Bad is phosphorylated at Ser136 by Akt, it is released from the proapoptotic complex and forms a complex with 14-3-3 proteins in the cytosol, therefore inactivating its proapoptotic function (46). Bad is hypothesized to be a downstream target of Akt in promoting cell survival (47). The present data revealed that AOPP-treatment inactivated Akt and Bad phosphorylation, while GLP-1 restored this suppression. These effects of GLP-1 were correlated with the attenuation of cell apoptosis. However, LY294002 abolished these effects of GLP-1. Therefore, the antiapoptotic effects of GLP-1 were associated with, at least in part, activation of the $\mathrm{PI} 3 \mathrm{~K} / \mathrm{Akt} / \mathrm{Bad}$ pathway.

Apoptosis is the process of programmed cell death, which is regulated through the balance between proapoptotic and antiapoptotic proteins. The Bcl-2 family, as the key regulators of apoptosis, consists of both proapoptotic proteins, including Bax and Bad, and antiapoptotic members, including Bcl-2 and Bcl-xL. The proapoptotic protein Bax is necessary for mitochondrial outer membrane permeabilization, inducing cytochrome $c$ release and leading to the activation of caspases (48). However, Bcl-2 inhibits this process by suppressing the translocation of Bax and therefore, reducing the activity of the caspases (49). Caspase-3 is a type of proteinase, which has a central role in the execution-phase of cell apoptosis only when it has been activated. Activation of caspase-3 requires proteolytic processing of its inactive zymogen into activated p17 and p12 fragments. Consistent with previous studies $(35,50)$, the present study demonstrated that AOPPs decreased the expression of $\mathrm{Bcl}-2$, and increased the expression of Bax and activation of caspase- 3 in H9c 2 cells. GLP-1 reversed these changes. Nevertheless, the effects of GLP-1 were partly abrogated by co-incubation with the PI3K inhibitor, LY294002. These findings suggested that the 
mechanism by which GLP-1 protects H9c2 cells against the apoptotic effects of AOPPs is by shifting the balance between proapoptotic and antiapoptotic proteins via the PI3K/Akt/Bad pathway.

The prominent finding of the present study was that GLP-1 protected cardiomyocytes against AOPP-induced apoptosis. The possible mechanism may be associated with the PI3K/Akt/Bad survival pathway. Currently, no single effective treatment exists for DCM. The present findings provided a conceivable mechanism of the development of DCM and rendered a novel application of GLP-1 exerting favorable cardiac effects for the treatment of DCM.

\section{Acknowledgements}

The present study was supported by grants from the National Natural Science Foundation of China (no. 81270966) and the Natural Science Foundation of Guangdong Province, China (no. S2012010009494). The authors would like to thank Dr Yulin Liao (Department of Cardiology, Nanfang Hospital, Guangdong, P.R. China) for generously providing the H9c2 cells. The authors appreciate the technical support from Guangdong Provincial Key Laboratory of Malignant Tumor Epigenetics and Gene regulation (Sun Yat-Sen Memorial Hospital, Sun Yat-Sen University, Guangdong, China).

\section{References}

1. Chen L, Magliano DJ and Zimmet PZ: The worldwide epidemiology of type 2 diabetes mellitus-present and future perspectives. Nat Rev Endocrinol 8: 228-236, 2011.

2. Battiprolu PK, Lopez-Crisosto C, Wang ZV, Nemchenko A, Lavandero S and Hill JA: Diabetic cardiomyopathy and metabolic remodeling of the heart. Life Sci 92: 609-615, 2013.

3. Schilling JD and Mann DL: Diabetic cardiomyopathy: Bench to bedside. Heart Fail Clin 8: 619-631, 2012

4. Kuethe F, Sigusch HH, Bornstein SR, Hilbig K, Kamvissi V and Figulla HR: Apoptosis in patients with dilated cardiomyopathy and diabetes: A feature of diabetic cardiomyopathy? Horm Metab Res 39: 672-676, 2007.

5. Fiordaliso F, Li B, Latini R, Sonnenblick EH, Anversa P, Leri A and Kajstura J: Myocyte death in streptozotocin-induced diabetes in rats in angiotensin II-dependent. Lab Invest 80: 513-527, 2000

6. Baraka A and AbdelGawad H: Targeting apoptosis in the heart of streptozotocin-induced diabetic rats. J Cardiovasc Pharmacol Ther 15: 175-181, 2010 .

7. Witko-Sarsat V, Friedlander M, Capeillère-Blandin C, Nguyen-Khoa T, Nguyen AT, Zingraff J, Jungers $P$ and Descamps-Latscha B: Advanced oxidation protein products as a novel marker of oxidative stress in uremia. Kidney Int 49: 1304-1313, 1996.

8. Kalousová M, Skrha J and Zima T: Advanced glycation end-products and advanced oxidation protein products in patients with diabetes mellitus. Physiol Res 51: 597-604, 2002.

9. Kaneda H, Taguchi J, Ogasawara K, Aizawa T and Ohno M: Increased level of advanced oxidation protein products in patients with coronary artery disease. Atherosclerosis 162: 221-225, 2002.

10. Atabek ME, Keskin M, Yazici C, Kendirci M, Hatipoglu N, Koklu E and Kurtoglu S: Protein oxidation in obesity and insulin resistance. Eur J Pediatr 165: 753-756, 2006.

11. Tabak O, Gelisgen R, Erman H, Erdenen F, Muderrisoglu C, Aral $\mathrm{H}$ and Uzun $\mathrm{H}$ : Oxidative lipid, protein and DNA damage as oxidative stress markers in vascular complications of diabetes mellitus. Clin Invest Med 34: E163-E171, 2011.

12. Guo ZJ, Niu HX, Hou FF, Zhang L, Fu N, Nagai R, Lu X, Chen BH, Shan YX and Tian JW: Advanced oxidation protein products activate vascular endothelial cells via a RAGE-mediated signaling pathway. Antioxid Redox Signal 10: 1699-1712, 2008.
13. Zhou LL, Hou FF, Wang GB, Yang F, Xie D, Wang YP and Tian JW: Accumulation of advanced oxidation protein products induces podocyte apoptosis and deletion through NADPH-dependent mechanisms. Kidney Int 76: 1148-1160, 2009.

14. Gaspari T, Liu H, Welungoda I, Hu Y, Widdop RE, Knudsen LB, Simpson RW and Dear AE: A GLP-1 receptor agonist liraglutide inhibits endothelial cell dysfunction and vascular adhesion molecule expression in an ApoE-/-mouse model. Diab Vasc Dis Res 8: 117-124, 2011.

15. Lønborg J, Vejlstrup N, Kelbæk H, Bøtker HE, Kim WY, Mathiasen AB, Jørgensen E, Helqvist S, Saunamäki K, Clemmensen $\mathrm{P}$, et al: Exenatide reduces reperfusion injury in patients with ST-segment elevation myocardial infarction. Eur Heart J 33: 1491-1499, 2012.

16. Kieffer TJ and Habener JF: The glucagon-like peptides. Endocr Rev 20: 876-913, 1999.

17. Tomas E and Habener JF: Insulin-like actions of glucagon-like peptide-1: A dual receptor hypothesis. Trends Endocrinol Metab 21: 59-67, 2010.

18. Liu Q, Anderson C, Broyde A, Polizzi C, Fernandez R, Baron A and Parkes DG: Glucagon-like peptide-1 and the exenatide analogue AC3174 improve cardiac function, cardiac remodeling, and survival in rats with chronic heart failure. Cardiovasc Diabetol, 9: 76, 2010.

19. Xie Y, Wang SX, Sha WW, Zhou X, Wang WL, Han LP, Li DQ and Yu DM: Effects and mechanism of glucagon-like peptide-1 on injury of rats cardiomyocytes induced by hypoxia-reoxygenation. Chin Med J (Engl) 121: 2134-2138, 2008.

20. Zhan Y, Sun HL, Chen H, Zhang H, Sun J, Zhang Z and Cai DH: Glucagon-like peptide-1 (GLP-1) protects vascular endothelial cells against advanced glycation end products (AGEs)-induced apoptosis. Med Sci Monit 18: BR286-BR291, 2012.

21. Newman RA, Hacker MP and Krakoff IH: Amelioration of adriamycin and daunorubicin myocardial toxicity by adenosine. Cancer Res 41: 3483-3488, 1981.

22. Zhou LL, Cao W, Xie C, Tian J, Zhou Z, Zhou Q, Zhu P, Li A, Liu Y, Miyata T, et al: The receptor of advanced glycation end products plays a central role in advanced oxidation protein products-induced podocyte apoptosis. Kidney Int 82: 759-770, 2012.

23. Ravassa S, Zudaire A and Díez J: GLP-1 and cardioprotection: From bench to bedside. Cardiovasc Res 94: 316-323, 2012.

24. Xie F, Sun S, Xu A, Zheng S, Xue M, Wu P, Zeng JH and Bai L: Advanced oxidation protein products induce intestine epithelial cell death through a redox-dependent, c-jun $\mathrm{N}$-terminal kinase and poly (ADP-ribose) polymerase-1-mediated pathway. Cell Death Dis 5: e1006, 2014.

25. Zhong ZM, Bai L and Chen JT: Advanced oxidation protein products inhibit proliferation and differentiation of rat osteoblast-like cells via NF-kappaB pathway. Cell Physiol Biochem 24: 105-114, 2009.

26. Valente AJ, Yoshida T, Clark RA, Delafontaine P, Siebenlist U and Chandrasekar B: Advanced oxidation protein products induce cardiomyocyte death via Nox $2 /$ Rac1/superoxide-dependent TRAF3IP2/JNK signaling. Free Radic Biol Med 60: 125-135, 2013.

27. Cai L, Wang Y, Zhou G, Chen T, Song Y, Li X and Kang YJ: Attenuation by metallothionein of early cardiac cell death via suppression of mitochondrial oxidative stress results in a prevention of diabetic cardiomyopathy. J Am Coll Cardiol 48: 1688-1697, 2006.

28. Kuethe F, Sigusch HH, Bornstein SR, Hilbig K, Kamvissi V and Figulla HR: Apoptosis in patients with dilated cardiomyopathy and diabetes: a feature of diabetic cardiomyopathy? Horm Metab Res 39: 672-676, 2007.

29. Piwowar A, Knapik-Kordecka M and Warwas M: Markers of oxidative protein damage in plasma and urine of type 2 diabetic patients. Br J Biomed Sci 66: 194-199, 2009.

30. Piwowar A, Knapik-Kordecka M and Warwas M: AOPP and its relations with selected markers of oxidative/antioxidative system in type 2 diabetes mellitus. Diabetes Res Clin Pract 77: 188-192, 2007.

31. Narula J, Arbustini E, Chandrashekhar Y and Schwaiger M: Apoptosis and the systolic dysfunction in congestive heart failure. Story of apoptosis interruptus and zombie myocytes. Cardiol Clin 19: 113-126, 2001.

32. Puddu A, Storace D, Durante A, Odetti P and Viviani GL: Glucagon-like peptide-1 counteracts the detrimental effects of advanced glycation end-products in the pancreatic beta cell line HIT-T 15. Biochem Biophys Res Commun 398: 462-466, 2010. 
33. Marzioni M, Alpini G, Saccomanno S, Candelaresi C, Venter J, Rychlicki C, Fava G, Francis H, Trozzi L and Benedetti A: Exendin-4, a glucagon-like peptide 1 receptor agonist, protects cholangiocytes from apoptosis. Gut 58: 990-997, 2009.

34. Harkavyi A and Whitton PS: Glucagon-like peptide 1 receptor stimulation as a means of neuroprotection. Br J Pharmacol 159: 495-501, 2010.

35. Ravassa S, Zudaire A, Carr RD and Diez J: Antiapoptotic effects of GLP-1 in murine HL-1 cardiomyocytes. Am J Physiol Heart Circ Physiol 300: H1361-H1372, 2011.

36. Ban K, Noyan-Ashraf MH, Hoefer J, Bolz SS, Drucker DJ and Husain M: Cardioprotective and vasodilatory actions of glucagon-like peptide 1 receptor are mediated through both glucagon-like peptide 1 receptor-dependent and -independent pathways. Circulation 117: 2340-2350, 2008

37. Bullock BP, Heller RS and Habener JF: Tissue distribution of messenger ribonucleic acid encoding the rat glucagon-like peptide-1 receptor. Endocrinology 137: 2968-2978, 1996.

38. Younce CW, Burmeister MA and Ayala JE: Exendin-4 attenuates high glucose-induced cardiomyocyte apoptosis via inhibition of endoplasmic reticulum stress and activation of SERCA2a. Am J Physiol Cell Physiol 304: C508-C518, 2013.

39. Timmers L, Henriques JP, de Kleijn DP, Devries JH, Kemperman H, Steendijk P, Verlaan CW, Kerver M, Piek JJ, Doevendans PA, et al: Exenatide reduces infarct size and improves cardiac function in a porcine model of ischemia and reperfusion injury. J Am Coll Cardiol 53: 501-510, 2009.

40. Ban K, Kim KH, Cho CK, Sauvé M, Diamandis EP, Backx PH, Drucker DJ and Husain M: Glucagon-like peptide (GLP)-1 (9-36) amide-mediated cytoprotection is blocked by exendin (9-39) yet does not require the known GLP-1 receptor. Endocrinology 151: $1520-1531,2010$
41. Huisamen B, Genis A, Marais E and Lochner A: Pre-treatment with a DPP-4 inhibitor is infarct sparing in hearts from obese, pre-diabetic rats. Cardiovasc Drugs Ther 25: 13-20, 2011.

42. Yao R and Cooper GM: Requirement for phosphatidylinositol-3 kinase in the prevention of apoptosis by nerve growth factor. Science 267: 2003-2006, 1995.

43. Mullonkal CJ and Toledo-Pereyra LH: Akt in ischemia and reperfusion. J Invest Surg 20: 195-203, 2007.

44. Shao S, Nie M, Chen C, Chen X, Zhang M, Yuan G, Yu X and Yang Y: Protective action of liraglutide in beta cells under lipotoxic stress via PI3K/Akt/FoxO1 pathway. J Cell Biochem 115: 1166-1175, 2014.

45. Chang G, Zhang P, Ye L, Lu K, Wang Y, Duan Q, Zheng A, Qin S and Zhang D: Protective effects of sitagliptin on myocardial injury and cardiac function in an ischemia/reperfusion rat model. Eur J Pharmacol 718: 105-113, 2013.

46. Datta SR, Brunet A and Greenberg ME: Cellular survival: A play in three Akts. Genes Dev 13: 2905-2927, 1999.

47. Datta SR, Dudek H, Tao X, Masters S, Fu H, Gotoh Y and Greenberg ME: Akt phosphorylation of BAD couples survival signals to the cell-intrinsic death machinery. Cell 91: 231-241, 1997.

48. Chipuk JE and Green DR: How do BCL-2 proteins induce mitochondrial outer membrane permeabilization? Trends Cell Biol 18: 157-164, 2008.

49. Dejean LM, Ryu SY, Martinez-Caballero S, Teijido O, Peixoto PM and Kinnally KW: MAC and $\mathrm{Bcl}-2$ family proteins conspire in a deadly plot. Biochim Biophys Acta 1797: 1231-1238, 2010.

50. Cunha DA, Ladrière L, Ortis F, Igoillo-Esteve M, Gurzov EN, Lupi R, Marchetti P, Eizirik DL and Cnop M: Glucagon-like peptide-1 agonists protect pancreatic beta-cells from lipotoxic endoplasmic reticulum stress through upregulation of $\mathrm{BiP}$ and JunB. Diabetes 58: 2851-2862, 2009. 